\title{
DEONTOLOGICAL PROBLEMS OF CLINICAL TOXICOLOGY IN BULGARIA, CONNECTED TO COMMUNICATION DIFFICULTIES, DURING THE DECADE 2000-2010
}

\author{
Marieta Yovcheva \\ Clinic of Intensive Treatment of Acute Intoxications and Toxoallergy, Naval \\ Hospital - Varna, Military Medical Academy - Sofia, Bulgaria.
}

\begin{abstract}
:
The specificity of clinical toxicology has always raised many deontological, medico ethical and legal problems, mainly connected to communication barriers, leading to distortion or total disappearance of the ability of the intoxicated patient to perceive and process the received information about his state and necessity of treatment, to agree or refuse medical help, to permit announcing data about his case. During the decade 2000-2010 significant changes in Health law, minor decrees and Medical Ethic Codes have been done, solving partially some of these questions. The new conceptions and conditions aroused new problems, connected with the intoxicated patient's autonomy, right to information, confidentiality, etc. The necessity of some adaptation of the official formulary of informed consent for clinical toxicology is discussed with accent on the dynamics of the process rather than on onemoment decision. A requirement of informed refusal by a whole sentence, free text, hand written by the patient, instead of simple signature is recommended. Current analysis and discussions of the deontological questions of toxicology are important.
\end{abstract}

Key words: deontology, clinical toxicology, communication, consciousness, competent, information, autonomy, duress, access, law

\section{INTRODUCTION}

Clinical toxicology is rich of specific and complex medico-ethical, deontological and legal problems. The basic problem usually is the toxic change of the mind that creates specific communication disorders. However, a number of additional psychological, medical and social factors influence the effective clinical communication between the doctor and the patient. Most of them are well known to the toxicologists and a lot of practical rules have been developed to copy with them.(1) The growing significance of patient's autonomy conception requires special attention to the specific needs of toxicological patients. $(2,3)$ Clinical toxicology is related to every other clinical discipline, so current analysis and discussions of the deontological questions of this discipline are important.

During the decade 2000-2010 significant changes in Health law, minor decrees and Medical Ethic Codes have been done, solving partially some of these questions.(4) The new conceptions and conditions aroused new problems, connected with the intoxicated patient's autonomy, right to information, confidentiality, relations of toxicologist with the patient's treating doctor for other diseases, family, employer, insurance agent, lawyer.

\section{AIM:}

Review of some of the most important old and contemporary deontological problems of the clinical toxicology in Bulgaria in the light of the changes during the decade 2000-2010 year. Outline of the main factors, leading to communication barriers in cases of intoxication. Suggestion is made for a form of dynamic assessment of consciousness in the process of informed consent of clinical toxicological patients.

\section{DISCUSSION}

The main factors creating communicative, deontological and judicial problems in clinical toxicology are: 1. High relative part of patients with temporary or constantly changed consciousness because of toxic encephalopathy, psychosis, stress, etc. Toxic changes of the mind lead to difficult or impossible perception and processing of the information as a consequence of the changed consciousness. Quick negative or positive dynamics in the mental status is typical for the acute intoxications. Temporary restriction of patient's autonomy in the process of management of an intoxicated patient is not unusual for toxicology practice. 2. High percentage of patients with suicidal attempts or different type of auto aggressive behavior. 3. High relative part of emergency toxicological cases, which require urgent admittance in hospital, diagnosis and treatment. 4. Medical procedures and manipulations which can be rejected by the patient because he considers them non pleasant or humiliating- stomach 
lavage, urethral catheterization, enema, extracorporeal detoxification of the blood, fixation or isolation of the patient and etc. 5. Frequent initial lack of information about a toxicological case; unclear or distorted history, simulation, dissimulation or aggravation. 7. High relative part of socially poor patients, patients with serious psychic acute or chronic diseases or with serious somatic co morbidity. 8. Expensive and long management and treatment of the severe intoxications. 9. Lack of enough information about the nature of the acute and chronic intoxications in society, including the patient's relatives, employers, media, and etc. 10. The health laws, decrees and orders do not reflect fully the specificity of the toxicological patients.

One of the most important goals of the contemporary deontology is the increased significance of the informed consent of the patient about his treatment at any stage of the diagnostic and treatment process. $(2,3,5,6,7,8)$ In Bulgarian Law of Health from 2005 it is fixed in section IIRights and obligations of the patient, in art. 84. (2), art. 86, $87,88,89,90,91$. (4). But in cases of acute intoxication, especially with direct or indirect psychotropic substances, the proper receiving of an informed consent by the patient is inconvenient, complicated or totally impossible at all stages of the process: a) assessing the competency of the patient; b) giving the information to the patient, his relatives and legal representatives in suitable form and volume; c) understanding of the information by the patient; d) voluntary consent of the patient; e) declaring the consent by the patient.(6) Partially these problems are solved in Health Law from 2005, art. 87. (1), (4), art. 89. (2), art. 90. (4), (5), but toxicological patients are not mentioned clearly as a special category. Sometimes this fact causes confusion in medics who treat an acute intoxication.

Acute intoxications need urgent diagnosis and treatment. The first hours are often decisive for the outcome (1). Sometimes the process of getting an informed consent or informed refusal by the patient, his relatives or legal representatives is too slow and complicated and delays the necessary medical help. In cases of diagnosed toxic change of the mind the doctor should better have the right to act in the best interest of the patient in due time. (9).

Clinical toxicological patients need a unification of the scale of mental changes. Nowadays many physicians use Glasgow coma scale (GCS), but it is too rough and in broad outline for the minimal mental changes at the beginning of an intoxication. GCS should be always used, but together with some more sensitive scale or with detailed description of the cerebral toxic syndrome. The scale of Reed and the scale of Bozhinov are more suitable but are not enough popular among doctors-non-toxicologists. The Mini Mental Status is suitable for use after the patient has been admitted in hospital.

The informed consent or informed refusal of toxicological help should not be just a formal signature. In practice an inadequate patient because of minimal or medium severe toxic changes of the central nervous system is capable of making a simple signature without realizing really the significance of it. The informed refusal of treatment should be made either by hand written whole sentence by the patient himself or by filling special formulary of refusal. If the doctor decides to accept the patient's refusal of treatment he should insist on the presence of the family or legal representative and once again inform about the possible risks.

The well known quick dynamics of the acute intoxications leads to additional complications of the process of receiving of an informed consent from a toxicological patient. Sometimes discrete changes of the mental function in the initial stage of intoxication predict quick deterioration and life-threatening complications. Although it is not a vital sign, the state of obnubilation (obtundation) of the consciousness has a primary significance for the decision of the doctor connected with the patient's competency and autonomy. A dynamic form for assessing the conscious and mental changes would be useful in the process of informed consent. In toxicological practice informal dynamic assessment has been always done and balance has been sought between the best patient's interest and optimal respect of the intoxicated patient's autonomy. For optimizing the dynamic evaluation of the mental status of an intoxicated person and the possibility of receiving informed consent from her/him, special formulary can be developed, like the example.

Table 1. Form example of dynamic assessment of the mental status of intoxicated patient in the process of receiving an informed consent/refusal for treatment of this intoxication.

\begin{tabular}{|l|l|l|l|l|c|}
\hline $\begin{array}{l}\text { Time of } \\
\text { examination }\end{array}$ & $\begin{array}{c}\text { First } \\
\text { examination }\end{array}$ & 4-th hour & 8-th hour & 12-hour & $\begin{array}{c}\text { 24-th hour } \\
\text { or more }\end{array}$ \\
\hline $\begin{array}{l}\text { Assessment of quantitative changes } \\
\text { of consciousness by the treating } \\
\text { physician(scale) }\end{array}$ & & & & & \\
\hline
\end{tabular}




\begin{tabular}{|l|l|l|l|l|l|}
\hline $\begin{array}{l}\text { Assessment of qualitative changes } \\
\text { of consciousness by } \\
\text { the treating physician }\end{array}$ & & & & & \\
\hline $\begin{array}{l}\text { Psychiatric and/or psychological } \\
\text { assessment }\end{array}$ & & & & & \\
\hline $\begin{array}{l}\text { Conclusion: Is the patient competent } \\
\text { at the moment to make } \\
\text { informed consent/refusal }\end{array}$ & & & & & \\
\hline
\end{tabular}

One of the important factors of the successful treatment in clinical toxicology is the good communication and interrelation between the doctor and patient. $(10,11,12)$ In many toxicological cases the temporary or constant change of consciousness makes this interrelation difficult or impossible. However when it is possible it has a positive effect on the diagnostic and treatment process because the patient is involved as an active participant in it. Even the partial including of the intoxicated patient as a partner in his management gives positive results. The doctortoxicologist should respect the right of his patient to be informed and if possible-actively involved in discussing the diagnostic and treatment plan. Communicating with a patient with toxic change of mind is a complex and difficult task for a physician, including verbal and non-verbal communicative abilities and experience. (2)

Of cause not all communication problems in clinical toxicology result directly from the intoxication. Some of the most important contemporary deontological and judicial problems in clinical toxicology are connected to a big group of patients with acute or chronic intoxications who do not have health insurance. Most of these patients suffer from complex social, financial, family, medical and psychological problems and often need more than one hospitalization. Often the intoxications of patients without health insurance are more severe and accompanied by depression or other co morbidity. In many cases such intoxications require complex, long and very expensive treatment. Suicide attempts are more frequent in this group. Chronic abuse and addiction are also more frequent. The absence of relatives and family in some cases, as well as the absence of personal general practitioner makes post hospital treatment and control of the health quite difficult. Even if the communication between the physician and such patient has been effective, the medical information and advices often are neglected due to these complex reasons. Nowadays all the intoxications in Bulgaria are treated equally without difference of health insurance status, according to the Constitution and the Law of Health, p. III, as urgent patients or on necessity. There is not definitive legal, administrative or other solution of this serious medical social problem of clinical toxicology, as part of the global problem of clinical medicine in Bulgaria. $(3,5)$

\section{CONCLUSIONS:}

Clinical toxicology is rich of specific communication problems due mainly to the toxic changes of the mind of the patient. The toxic cerebral syndrome has different time of onset, dynamics, clinical expression and dynamics in time.

Additional medical, psychological and social factors create clinical communicative and deontological problems in clinical toxicology.

With the contemporary growing significance of the patient's right of autonomy the medical ethical and deontology problems of clinical toxicology will become more complex. The changes in health legislation in Bulgaria during the last decade have led to progress in some "traditional" deontological and legal toxicological problems left unsolved others and created new ones.

The process of informed consent in toxicological cases has specific difficulties and should be adapted to the dynamic of communication capability of the patient. Even the partial including of the intoxicated patient as a partner in his management gives positive results. The doctortoxicologist should respect the right of his patient to be informed if/when possible and actively involved in discussing the diagnostic and treatment plan.

\section{REFERENCES:}

1. Monov Al., Clinical Toxicology, vol. I and II, Venel, Sofia, 1995. [in Bulgarian]

2. Radanov St. Medical Deontology. Siela. 2005. p. 83-140; p. 162-240. [in
Bulgarian]

3. Zinovieva D. Medical Law. Sofia. 2004. P. 23-29; p. 151-168; p. 223-231; p. 264-269. [in Bulgarian]

4. Law of Health. Prom. SG 70/10
Aug 2004. In force from $1^{\text {st }}$ of January 2005. [in Bulgarian]

5. Vodenicharov C, S. Popova, Medical Ethics. Sofia. 2003. p. 55-169. [in Bulgarian] 
6. Dimitrova S. The Informed Consent in Medical Practice. Alfamarket. Stara Zagora. 2003. p. 647. [in Bulgarian]

7. Lisaev P. Medical Deontology and Medical Law. Pleven. 2008. [in Bulgarian]

8. Donchev P. Medical Law and Deontology. Medicina i fizkultura. Sofia. 1992. p. 7-77; p. 129-142. [in Bulgarian]
9. Iovcheva M, Asparuhova M, Markova S. A Therapeutical Compulsion in Cases of Acute Selfpoisonings - Some Contemporary Deontological Problems. J of IMABGodishen sbornik (nauchni trudove). 1999, 5(2):224-225. [in Bulgarian]

10. Stoev V. Clinical Communication. Softtrade. 2011. [in Bulgarian]

11. Parker J, Coeira E. Improving
Clinical Communication. A View from Psychology. J Am Med Inform Assoc. 2000 Sep-Oct; 7(5):453-461. [PubMed] [CrossRef]

12. Simpson M, Buckman R, Stewart M, Maguire P, Lipkin M, Novack D, et al. Doctor-patient communication: the Toronto consensus statement. BMJ. 1991 Nov 30; 303(6814):1385-1387. [PubMed]

Address for correspondence:

Marieta Yovcheva

Clinic of Intensive Treatment of Acute Intoxications and Toxoallergy,

Naval Hospital - Varna, MMA - Sofia,

3, Hristo Smirnenski boul., 9000 Varna, Bulgaria

E-mail: rieta_js22@yahoo.com; 